\title{
Paws for a Study Break: Running an Animal Assisted Therapy Program at the Gerstein Science Information Centre
}

\author{
Allison Bell \\ Manager, Research \& Reference Unit \\ Gerstein Science Information Centre \\ University of Toronto \\ allison.bell@utoronto.ca
}

\section{Abstract}

The Gerstein Science Information Centre is the Science and Health Sciences library serving the University of Toronto community. As the second largest library on campus, Gerstein is a mecca for studying and can accommodate 1100 students. Research has shown that high levels of stress, anxiety, depression, and other mental health disorders are prevalent among both medical students and the student population as a whole. In recent years, Gerstein staff members have seen evidence of the rising levels of student stress in their dealings with the public while providing reference and research help. Animal-assisted therapy (AAT) is often used in hospital and rehabilitation settings and, most recently, to help young children learn to read by providing a stress-free learning environment in public libraries and schools. Studies on animal-assisted therapy have shown that AAT decreases blood pressure, cortisol, and reduces anxiety overall. In response to these findings, staff at Gerstein decided to implement an AAT program, "Paws for a Study Break," comprised of several sessions when a therapy dog and her handler would visit the library to hold 'office hours' and give students a break from their studying during the Winter 2012 exam period. Through a total of six visits of ninety minutes each, 417 visitors were received. Best practices and lessons learned are discussed, including steps involved in coordination of the event, working with volunteers, publicity avenues, dealing with media requests, costs involved, and evaluation techniques. Based on the completed evaluation forms, the response to the therapy dog program at Gerstein was overwhelmingly positive; students were very appreciative, and there are plans underway to repeat this program on an ongoing basis.

\section{Keywords}

animal-assisted therapy; students; stress; exams; dogs; event planning

\section{Background}

The Gerstein Science Information Centre is a locus of student studying on the University of Toronto St. George campus. The second largest library in the $\mathrm{U}$ of $\mathrm{T}$ system, Gerstein holds well over one million volumes of books, and has study space for 1100 students. Though the collection focuses on the Sciences and Health Sciences, 
students from a wide variety of disciplines choose this space to congregate for group work and also to engage in silent study in our quiet reading rooms.

Over the past few years, staff members at the public service desks in Gerstein have noticed an increase in agitated, anxious, and frustrated students seeking help at our public service desks and through our consultation service. The University of Toronto is a very competitive institution: a place where students who were at the top of their class in high school may find themselves having to work much harder to maintain a place closer to the middle, all the while feeling pressure to succeed. Additionally, attending university is a major life transition for many students, especially for those living away from home for the first time. Students are bombarded with information not only in their classes but also from social media and the internet in general. Add to that the pressure of exams each term. At Gerstein we wanted to find a way to provide a few moments of relief for the students who come to the library to study.

\section{Literature Review}

Several studies have shown that medical students (one of Gerstein Library's target populations) in particular may suffer from increased stress and anxiety (Abdulghani; Chang; Dyrbye) though the problem extends to many post-secondary students in general. According to the Spring 2012 National College Health Assessment in the United States, more than $50 \%$ of students reported feeling "exhausted", "lonely", "sad" and/or "overwhelming anxiety," and $86 \%$ reported that they "felt overwhelmed by all [they] had to do" (American College Health Association, 13-14).

In considering the various avenues for stress-reduction in students, we found numerous studies with evidence supporting the healing and stress-reducing potential of therapy dogs and other animals (Barker; Shiloh; Friedman; Odendaal; Wilson; Baun). Shiloh's study demonstrated that "a short period of petting an animal resulted in reduced stateanxiety among....individuals in a stressful situation" (n.p.). Baun states that "studies have shown that petting a ... dog decreases blood pressure in healthy subjects" (19). Friedman notes that "Interacting with a therapy dog for 5 minutes led to decreased serum and salivary cortisol..." (88).

Several institutions have seen the correlation between their stressed-out students and the benefits derived from therapy animals and have implemented programs to integrate the two. Educational sites such as Yale Law (Checking Out Monty), Harvard Libraries (Cooper, the Countway Library Therapy Dog), UBC Faculty of Law (A Little Dog Therapy Goes a Long Way), Dalhousie Students' Union (McNutt) and others have recently publicized visits from therapy dogs, and the students have reportedly been very enthusiastic and happy to have the opportunity to pet and play with the animals.

Considering the compelling research combined with evidence of the success of other therapy dog programs at similar post-secondary institutions, the staff at the Gerstein Science Information Centre collaborated to host a series of visits from Bella, a St. John Ambulance Therapy Dog, during the Fall 2012 exam period. Though initially involving a 
large amount of coordination, by sharing the steps and considerations involved, our hope is that this event will be more easily replicable at another time or across other institutions.

\section{Program Description}

Bella the Therapy Dog and her handler/owner Deb visited the library six times, on Wednesdays and Thursdays from November 28 to December 13, 2012, from 1:30-3:00 pm. A member of the Research and Reference team was present for each visit to count attendance, encourage students to fill out evaluation forms, answer questions, and generally supervise the event. The program was a great success, with a total of 417 students and staff able to meet with Bella over the six visits. Organization of the event required planning and coordination both before and during the timeframe of the visits.

\section{Planning the Visits}

The Research \& Reference Unit at Gerstein provides research and information service to students, staff and faculty through the Information Desk, one-on-one consultations, and classroom instruction. Therefore, it seemed very appropriate that the idea for relieving the stress so often observed by front-line staff should be coordinated by this department and hosted by the library. Research on therapy dog visits to other institutions showed that these programs have many benefits that outweigh potential drawbacks. Potential drawbacks that were considered included: extra cleaning required in the area where the visits would be taking place to remove dog hair, nose prints on glass, etc.; potential for student complaints if they were allergic to/afraid of dogs; increased noise in the library during a key study time; and potentially more students attending the event than the room or the dog could handle. With these considerations in mind, several pieces had to come together in order to get the program off the ground successfully. This was time-consuming but not difficult. In retrospect, having two people responsible for planning the program would have reduced the time commitment and labour intensity experienced by the one planner.

\section{Coordination with Volunteer(s)}

There are several organizations that run animal-assisted therapy programs, most often involving visits with hospitals, retirement homes, long-term care facilities and, most recently, with young students learning to read. Some of these organizations serving Ontario include: Caring Canine (http://www.caringcanine.ca), Therapeutic Paws of Canada (http://tpoc.ca/), St. John's Ambulance (http://www.sja.ca/Canada/COMMUNITYSERVICES/PROGRAMS/Pages/TherapyDogS ervices.aspx), and Therapy Tails (http://www.therapytails.ca/). For this project, the organizer made contact with the coordinator of the St. John's Ambulance Therapy Dog program in Toronto.

In the initial phone conversation, the Therapy Dog Program Coordinator was interested in hearing a description of the kind of service Gerstein library hoped to provide and what 
outcomes were being sought for our students. Also discussed were the preferred times and dates for the visits. After this conversation, it took the Coordinator about one month to find a volunteer with the program who was willing to travel to our location on or around the dates indicated. This delay may have been because we were looking for one volunteer to cover six visits in total. If the library was looking for only one or two visits, the time to find a volunteer would likely have been much shorter.

The initial meeting with Bella, the therapy dog, and her handler Deb, was in the space in the library designated to host the visits. This was to make sure that they felt comfortable, found the space appropriate, and to discuss logistics in person. In this meeting it was decided the library would host six visits of ninety minutes each. St. John's Ambulance therapy dogs generally visit for one hour at a time; a two hour visit was initially considered, but it was decided that ninety minute visits would be long enough for more students to be able to attend, but short enough that the dog wouldn't be overly exhausted by the end of the visit. Visits would take place two days per week (Wednesdays and Thursdays) over a span of three weeks. It was felt that the first week might be a bit slower, and the number of attendees would grow as word of the program got around. The decision was made to start the program the week before exams began and continue through the busiest two weeks of the exam period.

\section{Volunteer Compensation}

The St. John's Ambulance Therapy Dog program is staffed entirely by volunteers and does not require any compensation be given from hosts to therapy dog handlers.

However, our volunteer was willing to give significant time and energy to the visits, and in exchange the library offered to pay for her parking and mileage as a goodwill gesture. The therapy animal organization may be able to suggest preferred or acceptable forms of compensation. For example, organizations may allow hosts to cover parking costs but may not allow their volunteers to accept gifts from clients. Formal reimbursement terms should be set out before the visits commence.

\section{Location of the Visits in the Library}

One significant consideration was where to hold the visits. The visits should not disrupt students who were studying, while at the same time making it easy for them to find Bella if they needed a little break from their work. Several people (staff and students) suggested walking the dog through the library to visit with students where they sat, but it was felt this would be too disruptive for those not wishing to visit with the dog, and in some students it may have caused even more anxiety if they were allergic to or afraid of dogs, or if students came over to pet the dogs and made noise in the silent study hall. It was decided that the visits would be held in a large group study room just off the main Reading Room in the library. The door to the study room was kept closed, though it was clear glass so that students could see Bella was inside. A poster was also situated on an easel outside the room, which was visible to students studying in, or passing through, the Reading Room. 
During the first week of the program, we provided coffee and candy in the room but found that students weren't interested in the refreshments. For the remaining two weeks, the snacks were discontinued, but we still saw a major increase in the number of attendees.

One challenge was figuring out the proper furniture set up in the room during visits. Though it was a large room with lots of seating, the students tended to congregate right inside the door rather than moving around in the room, and they would sit on the floor rather than in the many chairs available. Clearing furniture out of the center of the room provided ample floor space that was readily used by students. It was heartwarming to see a group of students, mostly strangers to one another, forming a spontaneous circle on the floor, with Bella walking around the circumference visiting everyone in turn.

\section{Publicity and Media}

Publicity was a team effort. Once the dates and times were confirmed, a poster was created. This poster was displayed in the main lobby of the library and directly outside the room where Bella was situated. It was also posted digitally to our Facebook page and the Gerstein Science Information Centre webpage. A display was created for the lobby consisting of books in our collection on animal-assisted therapy, articles about the topic, and bookmarks that students could take away with them with the dates, times and location of the visits. A publicity statement about the event was created and sent to the Communications Librarian, who in turn posted it on the University of Toronto libraries website and drafted a media release which was sent to University of Toronto contacts as well as local media outlets.

On the days of the visits, a staff member made an announcement over the PA system letting students know that Bella the therapy dog had arrived and how long she would be in the library. Though initially worried that there might be complaints about the intrusiveness of these announcements (our PA system broadcasts throughout the library, including the silent study areas and graduate student offices), it was found that this was an excellent way of promoting the service. After these announcements there was always a rush of people who came to visit Bella, many of whom indicated they were unaware of the program until they heard the announcement.

\section{Media Considerations}

An unexpected source of publicity was the local news media. It was thought that our small pilot project would likely go unremarked upon except by the $U$ of $T$ libraries, so it was a shock to the organizers when it garnered television media attention. After the press release went out through the Communications Librarian, there were several requests for interviews as well as requests to take photos and videos of Bella interacting with the students. As this was the first occurrence of "Paws for a Study Break" at Gerstein, we were excited to be getting any publicity and so agreed to all media requests. However, in hindsight, media requests for photos, filming, interviews, etc. should be considered carefully before agreeing to participate. They were found to be 
both a boon and a barrier to the success of the program. Though the media coverage helpfully spread the word to the wider community, it was also found to be disruptive for the students and volunteers to have a camera around. Feedback from one student indicated that she avoided the event altogether because she saw a camera in the room when she came to visit.

Before agreeing to media coverage of the event, it is recommended that strict limits be set for filming and/or photography. In many cases, to use video or still images of students, the media will have to obtain their permission. For our sessions there were several copies of University of Toronto release forms available for students to sign in case the opportunity for a good photo arose. Media outlets should know what kind of permission they require. Allow filming or photography for a limited time only during the session, and have interviews taped away from the therapy dog location so that students can still enjoy the dog while filming is going on. It is suggested to allow filming for no more than ten to twenty minutes in the room where the dog is interacting with students. This recommendation comes from one negative experience at Gerstein, when a local news camera crew stayed the full ninety minutes of the visit. The organizer declined to say anything, being torn between the thought of the positive publicity this could generate and the inconvenience for students. As a result, the turnout that day was only half the attendance on the other days, as many students chose to stay away when they saw the cameras. In the future we will remember that although the media attention is exciting, the therapy dog visits are for the benefit of the students first!

\section{Time Spent}

Any new program will be somewhat time-consuming the first time it is run, with gradual improvements over subsequent repetitions. Coordinating with a volunteer-based organization and involving several staff members to assist with various publicity methods can also be time-consuming. "Paws for a Study Break" at Gerstein was initiated in the beginning of September 2012, and the first visit took place on November 28,2012 , with the bulk of coordination being done in early November before the visits commenced.

As mentioned previously, it took approximately one month to find a volunteer who was available to travel to our location on the dates and times specified. The more visits and time required, the more of a challenge it may be for the animal-assisted therapy organization to find a volunteer willing and able to accommodate your request. The visits to Gerstein were scheduled for mid-day during the week. Many volunteers may have better availability during evenings or weekends. Due to the large amount of administrative detail to sort out right before the visits, our official media release did not go out until the end of the first week of visits. Once this was released, the attendance numbers rose steeply.

A significant amount of time was spent by various staff members monitoring social media channels throughout the three-week program. Once the poster was linked on our Facebook page, the page itself had a surge in popularity, with numerous students 'liking' 
it, and staff, students, and members of the public 'sharing' the link to our poster. There were numerous comments on our page, and every time a media outlet covered our program it was also linked on Facebook. Twitter was also used as a publicity tool and was monitored on the days of the visits so that posts by students about the therapy dog program could be 'retweeted' to our followers. Many students took photos of Bella while visiting, and a few of these ended up on Twitter as well (see Appendix B).

One of the most significant amounts of time spent was in attending and monitoring each visit. This meant going down to the room in advance to set up, staying for the ninety minute session and then seeing Deb and Bella out at the end of the visit. As this was the inaugural deployment of this project, we wanted a staff member present to be able to answer questions about the library or the university if asked, to direct students to fill out the evaluation forms, and also to be there for 'security' purposes in case any situations arose in which the volunteer felt uncomfortable (problem students, rowdy behavior, etc.) - though thankfully the latter did not occur. Though this turned out to be very worthwhile for research and assessment purposes, in the future delegating or alternating this task with willing library staff members would make the program less of a time burden for one person. Deb, our volunteer handler, was a former educator, so she had no problem talking with students, explaining the therapy dog program and answering the same questions over and over. However, if a volunteer was more reserved, it would be nice to have a staff member present willing to engage the students in chat as many of them were eager to ask questions and to share stories of their pets at home. Another reason to delegate to volunteer staff members is so that they can also spend some time with the therapy dog. It isn't just the students that benefit from the visits!

Finally, staff time was spent in collating the feedback gathered through the paper and online feedback forms (see Appendix A).

\section{Evaluation}

Program evaluation was conducted using a variety of methods. In the room there were paper evaluation forms which students were encouraged to fill out. The same form was also created online using SurveyMonkey, and bookmarks with the survey address were placed in the room for students to take away with them (see Appendix A). Students seemed to prefer the paper forms (sixty-two responses received in paper compared to fifteen online), most likely because of their availability in the room combined with staff encouraging students to fill them out before leaving. However, having the online forms was useful as when the room was full, handing out bookmarks with the web address was much easier than having students try to fit around the table to complete the paper forms. The online survey was also publicized on Facebook and Twitter to capture people who had visited with Bella but had not filled in the paper form.

A staff member stayed in the room throughout the duration of the visits, making conversation with visitors, taking note of the number of attendees, writing down 
comments, and generally observing interactions. Twitter and Facebook were monitored before and after the visits took place, and comments were recorded (see Appendix B).

\section{Discussion}

Over the six visits, there were a total of 417 students and staff who stopped in to visit with Bella. Visits ranged from thirty seconds just to 'see' the dog, to a few students who stayed sixty minutes or more, petting Bella, chatting with the handler and other students, or just sitting quietly in a comfortable chair.

A compilation of our online and paper evaluations forms had a response rate of $18.5 \%$. Of these respondents, $82 \%$ rated the event as excellent and $100 \%$ indicated they would be interested in attending a similar event in the future. It was surprising to see that Medicine was identified by only one student participant, considering that Gerstein is the primary library serving this highly competitive and very stressful program. However, the library is centrally located and thus is a study hub for students from all disciplines. Based on this finding, in the future we may target more marketing materials directly at the Faculty of Medicine to try to encourage medical students to 'Paws for a Break' at Gerstein.

The responses to the questions 'How would you rate the event?', 'How likely are you to recommend the event?', and 'How likely are you to attend a similar event in the future?' were so overwhelmingly positive that plans are underway to repeat this program for the Spring 2013 exam period in April.

One missed opportunity was the comparison of Facebook page 'likes' before and after the event, as well as recording the number of Twitter followers before and after. We neglected to record the number of likes and followers we had prior to the event, but both the Facebook and Twitter administrators noticed a significant upswing in the number of likes and followers received during and after the visits took place. For visits in the future this is something to be monitored more mindfully.

Another missed opportunity was that the survey was constructed with the hope of gauging the success of the event and whether students would be interested in having regular visits from a therapy animal. As mentioned in the literature review, previous studies have supported the healing and stress-reducing potential of therapy dogs, and it is believed that our experiment had a similar desired effect. However there were no questions included which specifically asked participants to indicate their stress levels before and after the visits. In the future, it would be worthwhile to try to assess to what extent students felt a reduction in their stress levels after the visits.

\section{Conclusion}

Studies from around the world show that students are especially prone to feeling overwhelmed by the work expected of them and likely to suffer from general stress and 
anxiety through their post-secondary careers. Much of the research on animal-assisted therapy has been done with patients in the hospital, in rehabilitation, or with pet owners themselves. However the results can be applied to the student situation with success, as shown in the many instances of post-secondary institutions offering AAT during exams or at other times of the year.

Based on the lessons learned from this pilot project, future visits should be easier and less time-consuming to organize. For libraries considering implementing a therapy dog program, especially one with multiple visits and/or multiple animals, it would be helpful to have two coordinators involved in organizing the program. Interested staff members can be encouraged to take part, perhaps by sitting in on one or two visits, thus lessening the time required by the organizers. Staff members can also contribute by publicizing and monitoring social network channels, creating related displays, making announcements when the visits begin, and creating signage to advertise the event.

It was worthwhile having both online and paper forms to evaluate the visits, even though the majority of feedback was collected on paper. Giving people bookmarks with the online form web address was much more efficient than trying to convince people to fill out the paper forms when then room was full. Also, this way one can publicize the forms through social media and hopefully catch people who didn't take the time to fill out the paper forms while they were visiting.

Students, staff and even the media gave overwhelmingly positive reviews to the "Paws for a Study Break" program at the Gerstein Science Information Centre. The library plans to continue offering similar visits for students in the future, with the next visits with Deb and Bella planned for the Spring exam period in 2013.

\section{Works Cited}

"A Little Dog Therapy Goes a Long Way." University of British Columbia, Faculty of Law at Allard Hall n.d. Web. 11 Feb. 2013.

<http://www.law.ubc.ca/news/2012/dec/12 0612 dogs.html>.

Abdulghani H.M., A.A. AlKanhal, E.S. Mahmoud, G.G. Ponnamperuma, and E.A. Alfaris. "Stress and Its Effects on Medical Students: A Cross-sectional Study at a College of Medicine in Saudi Arabia." Journal of Health, Population, and Nutrition 29.5 (2011): 516-522. Web. 11 Feb. 2013.

American College Health Association. "Spring 2012 Reference Group Executive Summary." National College Health Assessment. 2012. Web. 11 Feb. 2013. $<$ http://www.acha-ncha.org/docs/ACHA-NCHA II ReferenceGroup ExecutiveSummary Spring2012.pdf>. 
Allen, Jane E. "Checking Out Monty: Yale Law Students Can Reduce Stress with Therapy Dog." ABC News Medical Unit. March 24, 2011. Web. 11 Feb. 2013. $<$ http://abcnews.go.com/Health/StressCoping/checking-monty-yale-law-studentsreduce-stress-therapy/story?id=13206568\#.UJKgrlmhnVY>.

Barker, Sandra B., Janet S. Knisely, Nancy L. McCain, Christine M. Schubert, and Anand K. Pandurangi. "Exploratory Study of Stress Buffering Response Patterns from Interaction with a Therapy Dog" Anthrozoos, 23:1 (2010): 79-91. Web. 11 Feb. 2013.

Baun, Mara, Kathryn Oetting, and Nancy Bergstrom. "Health benefits of Companion Animals in Relation to the Physiologic Indices of Relaxation." Holistic Nursing Practice. 5:2 (1991): 16-23. Web. 11 Feb. 2013.

Chang, Elaine, Florence Eddins-Folensbee, and John Coverdale. "Survey of the Prevalence of Burnout, Stress, Depression, and the Use of Supports by Medical Students at One School." Academic Psychiatry 36 (2012): 177-182. Web. 11 Feb. 2013.

"Cooper, the Countway Library Therapy Dog." Countway Library (Harvard University) n.d. Web. 11 Feb. 2013. $<$ https://www.countway.harvard.edu/menuNavigation/aboutCountway/cooper.htm l>.

Dyrbye L.N., M.R. Thomas, and T.D. Shanafelt. "Systematic Review of Depression, Anxiety, and Other Indicators of Psychological Distress among U.S. and Canadian Medical Students." Academic Medicine. 81.4 (2006): 354-373. Web. 11 Feb. 2013.

Friedman, Erika, Heesook Son, Chia-Chun Tsai. "The Animal-Human Bond: Health and Wellness." Handbook on Animal-Assisted Therapy: Theoretical Foundations and Guidelines for Practice. Ed. Aubrey H. Fine. London, U.K.: Academic Press, 2010. 85-110. Web. 11 Feb. 2013

McNutt, Ryan. "Dal Goes to the Dogs: DSU's 'Puppy Room' a Big Hit." Dal News. 5 Dec. 2012. Web. 11 Feb. 2013. <http://www.dal.ca/news/2012/12/05/dal-goes-to-thedogs.html>.

Odendaal, J.S.J. "Animal-Assisted Therapy - Magic or Medicine?" Journal of Psychosomatic Research. 49:4 (2000): 275-280. Web. 11 Feb. 2013.

Shiloh, Shoshana, Gal Sorek, and Joseph Terkel. "Reduction Of State-Anxiety By Petting Animals In A Controlled Laboratory Experiment." Anxiety, Stress \& Coping: An International Journal. 16.4 (2003). 387-395. Web. 11 Feb. 2013. 
Wilson, Cindy. "The Pet as an Anxiolytic Intervention." The Journal of Nervous and Mental Disease. 179:8 (1991): 482-489. Web. 11 Feb. 2013.

\section{Media Coverage of the Paws for a Study Break Event}

Mitchell, Liam. "A Bark before the Break: Therapy Dogs Among Initiatives to Relieve Students' End-of-Term Stress." U of T News. 6 Dec. 2012. 12 Feb. 2013. $<$ http://www.news.utoronto.ca/bark-break>

Piunno, Andrea. "How Dogs Help Students Fight Stress." CityNews Toronto.: 12 Dec. 2012. Web. 12 Feb. 2013. <http://www.citynews.ca/2012/12/12/how-dogs-helpstudents-fight-stress $>$.

"U of T Hosts Therapy Dog Sessions for Stressed Students." Global News. David Shum: 6 Dec. 2012. Web. 11 Feb. 2013. <http://globalnews.ca/news/316677/u-of-thosts-therapy-dog-sessions-for-stressed-students/>. 


\section{Appendix A: "Paws for a Study Break" Event Feedback Form}

Total \# of Visitors: 417

Total \# of Responses Received: 77 (18.5\% Response Rate; 15 online, 62 on paper)

What is your status?

Undergraduate student* [59] Visiting Researcher

Faculty member*

Graduate student*[15]

University staff

Library staff [4]

Other [1]

For statuses with an *, please fill out the following:

*Department:

Political science [5]

Languages [3]

Arts \& Sciences [6]

Humanities \& Soc. Sci. [6]

Life Sciences [7]

Health Sciences [1]

Engineering [1]

Why did you come to the library today? (check all that apply)

Study for exams [47]

To visit with therapy dog [37]

Study (general) [8]

Use the computers [1]

Work on an assignment [9]

Meet with library staff [2]

Other [2]

How did you hear about 'Paws for a Study Break?' (check all that apply)

Library webpage [11]

Sign or display in the library [34]

Twitter [3]

Facebook [19]

From a friend [21]

Saw the event happening and decided

to attend [8]

From a library staff member [10]

Other [4 - heard the announcement]

Overall, how would you rate the 'Paws for a Study Break' event?

$\begin{array}{lll}\text { Excellent [63] } & \text { Very good [13] } & \text { Fairly good [1] } \\ \text { Mildly good } & \text { Not good at all } & \end{array}$

How likely are you to recommend the event to a friend?

Extremely likely [58] $\quad$ Very likely [17] Moderately likely [2]

Slightly likely

Not at all likely

Would you be interested in attending a similar event in the future?

Yes [77] No Unsure

Selected Comments:

-Everyone was very visibly happy to see Bella. :) it definitely brightened my day

-It was a nice break from staring at my exam material. Bella was adorable! 
The dog, Bella, was so sweet and gentle. Her owner was also very pleasant to interact with. I wish I could take Bella home with me!

-Camera crews from local news channel overstayed their welcome a bit, interrupting student time with Bella.

-Please make this is a regular thing!!

-I hope this happens again in the future and in more locations!

\section{Appendix B: Facebook and Twitter Response}

\section{Facebook}

This is a screenshot from the Gerstein Science Information Centre facebook page showing the 10 most popular posts (sorted by number of 'Engaged Users') between February 2012 and March 2013. Posts about Bella are \# 1, 3, 6, 7, and 8. Post \#1 "Starting tomorrow!" is the initial announcement including the poster shown in Appendix C. "Engaged Users" is defined on Facebook as "...the number of people who have clicked anywhere on your post." As you can see, the number of 'engaged users', people 'talking about this,' and the 'virality' of the post far exceed the next most popular posts.

\section{Gerstein Science Informati... $\quad$ Timeline -}

\begin{tabular}{|c|c|c|c|c|c|c|}
\hline Date? & Post ? & Reach? & $\begin{array}{l}\text { Engaged } \\
\text { Users? }\end{array}$ & $\begin{array}{l}\text { Talking About } \\
\text { This? }\end{array}$ & Virality? & \\
\hline $11 / 27 / 12$ & 圆 Starting tomorrow! All staff and stud... & 235 & 393 & 96 & $40.85 \%$ & का \\
\hline $11 / 27 / 12$ & 圆 We have put up a display on insulin ... & 205 & 74 & 2 & $0.98 \%$ & ศा \\
\hline $12 / 4 / 12$ & [回 Bella the therapy dog from St. John ... & 238 & 72 & 22 & $9.24 \%$ & का \\
\hline $3 / 20 / 13$ & [圆 Gerstein Events & 380 & 51 & 12 & $3.16 \%$ & का \\
\hline $2 / 8 / 13$ & 回 Various views around Gerstein durin... & 130 & 40 & 11 & $8.46 \%$ & 丹 \\
\hline $12 / 6 / 12$ & 에 Read about Bella and other ways to ... & 173 & 37 & 11 & $6.36 \%$ & ศा \\
\hline $11 / 29 / 12$ & 中 Have you been to visit with Bella, the... & 206 & 25 & 3 & $1.46 \%$ & ศा \\
\hline $12 / 7 / 12$ & क] UofT students, staff...and Bella, mak... & 128 & 22 & 2 & $1.56 \%$ & Fा \\
\hline $11 / 9 / 12$ & 圆 Our new water bottle refilling station. & 189 & 16 & 3 & $1.59 \%$ & का \\
\hline $2 / 8 / 13$ & 이 The library will be closing today at $3 \ldots$ & 88 & 15 & 5 & $5.68 \%$ & ศा \\
\hline
\end{tabular}

\section{Selected Tweets:}

@UTMedAdmissions 13 Dec: Great idea U of T Libraries! How dogs help students fight stress- CityNews.ca http://www.citynews.ca/2012/12/12/how-dogs-help-students-fightstress via @topscms 
@mona_antonia 6 Dec: LOL petting Bella the Stress Relief dog at Gerstein actually made me smile, what a great idea :') \#UofTsolutions

@UofT_Liam 5 Dec: \#UofT's own puppy room! “@GersteinLibrary: Bella will also be here tomorrow, and next Wednesday, Thursday:

http://www.facebook.com/photo.php?fbid=10151300806241418\&set=a. 1015130080622 6418.515834.60080681417\&type $=1$ \&theater ..."

@shaanzeheh 29 Nov: This is happening every Wednesday and Thursday 1:30-3 till Dec 13th in Gerstein! http://instagr.am/p/Sn8FfTlt8c/

@Reem_meissa 29 Nov:

Gerstein Library has a therapy dog for exam-stress relief, so adorable! \#UofT

\section{Appendix C: Poster Advertising the Event}

Poster was used in lobby, outside Marvin Gerstein Room, and on Facebook to publicize Bella's visits.
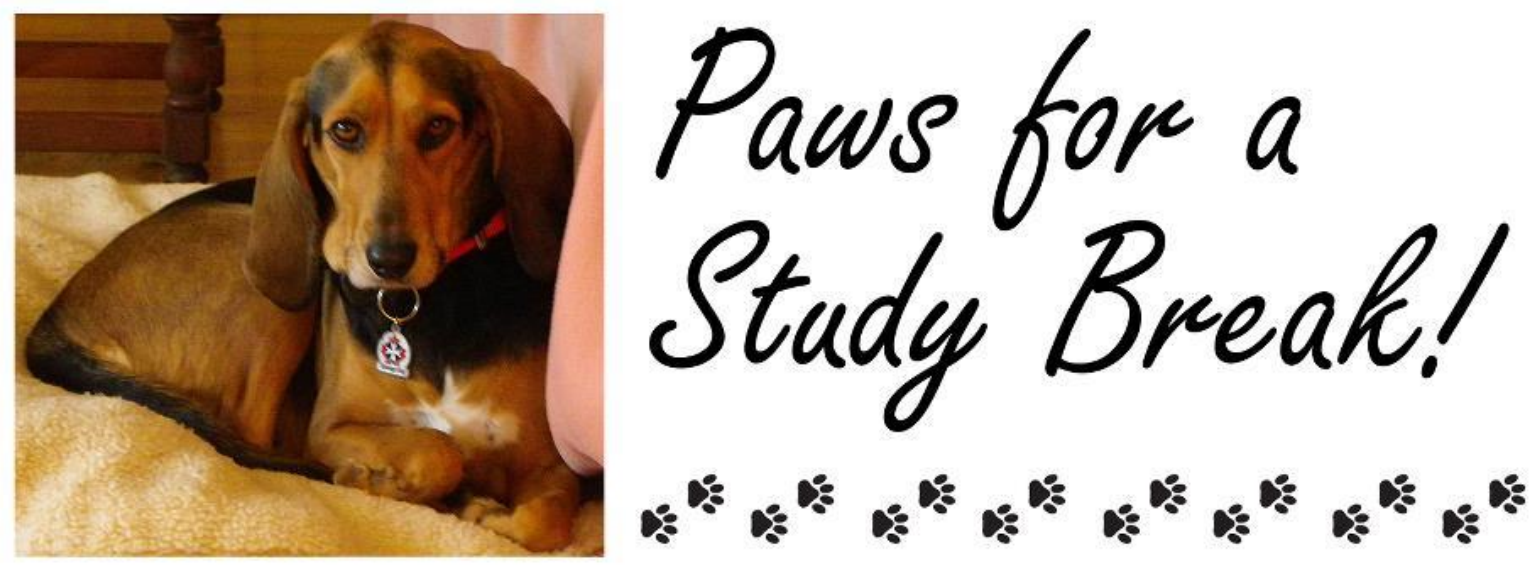

Bella, a therapy dog from St. John Ambulance, will be visiting the library to relieve exam stress.

Paws for a break, come pet \& play with her!

Where: Marvin Gerstein Room (1st Floor of the library)

When: Wednesdays and Thursdays, Nov 28 - Dec 13

Time: $1: 30-3: 00 \mathrm{pm}$

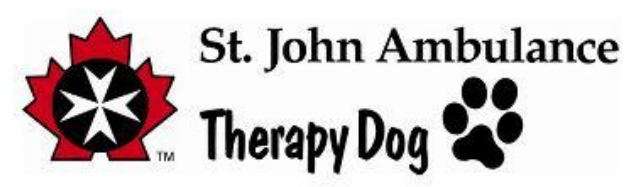

